Bacillus Calmette-Guerin administered to rats resulted in decreased aniline hydroxylase activity. Recently, we found that BB activated C3 in serum complement components might be produced via an alternative pathway. Details of the relationship between their biological activity and the antitumor effect of $\mathrm{BB}$ will be reported elsewhere.

\title{
REFERENCES
}

1) Kato, N., Ito, S., Yamazaki, M. And Mizuno, D.: Effect of Proteus vulgaris lipopolysaccharide on resistance of mice inoculated with tumor cells sensitized to Ehrlich carcinoma transplantation. Gann 64, 111-120 (1973)

2) Bober, L.A., Kranepool, M.J. and Hollander, V.P.: Inhibitory effect of endotoxin on the growth of plasma cell tumor. Cancer Res. 36, 927-929 (1976)

3) Azuma, I., Yamamura, Y. ANd Ribi, E.: Preparation adjuvant-active, tuberculin-free peptidoglycolipid from human tubercle bacilli. Japan. J. Microbiol. 18, 327-332 (1974)

4) Ito, H., Fusi, K., Naruse, S. AND Miyazaki, T.: Studies on antitumor activity of Basidiomycete polysaccharides. Antitumor effect of fungal and bacterial polysaccharides on mouse tumors. Mie Med. J. 23, 117-127 (1973)

5) Ito, H., Sugiura, M. AND MiYAZAKI, T.: Antitumor polysaccharide fraction from the culture filtrate of Fomes fomentarius. Chem. Pharm. Bull. 24(10), 2575 (1976)

6) Miyazaki, T., Oikawa, N., Yadomae, T., Yamada, H., Yamada, Y., Hsu, H.Y. and Ito, H.: Relationship between the chemical structure and antitumor activity of glucans prepared from Grifola umbellata. Carbohydr. Res. 69, 165-170 (1979)

7) Middlebrook, G. AND Dubos, R.J.: Specific serum agglutination of erythrocytes sensitized with extracts of tubercle bacilli. J. Exp. Med. 88, 521-529 (1948)

8) La Du, B.B., Gaudette, L., Trousof, N. and Brodie, B.B.: Enzymatic dealkylation of aminopyrine (pyramidon) and other alkylamines. J. biol. Chem. 214, 741-752 (1955)

9) Kato, R. AND Gillette, J.R.: Effect of starvation on NADPH-dependent enzymes in liver microsomes of male and female rats. J. Pharmacol. exp. Ther. 150, 279-284 (1965)

10) Lowry, O.H., Rosebrough, N.J., Farr, A.L. and Randall, R.J.: Protein measurement with the folin phenol reagent. J. biol. Chem. 193, 265-275 (1951)

11) Farquhar, D., Loo, T.L., Gutterman, J.U., Hersh, E.M. and Luna, M.A.: Inhibition of drug metabolizing enzymes in the rat after Bacillus Calmette-Guerin treatment. Biochem. Pharmacol. 25, 1529-1535 (1976)

\section{SCHEDULE DEPENDENT CHANGE OF PUNISHED RESPONDING AFTER DIAZEPAM IN RATS}

\author{
Hisashi KURIBARA and Sakutaro TADOKORO \\ Division for Behavior Analysis, Behavior Research Institute, School of Medicine, \\ Gunma University, 3-39-22 Showa-machi, Maebashi 371, Japan
}

Accepted November 22, 1979

It has been considered that, in the preclinical drug assay, punishment experiment is one of the best methods to evaluate an anti-anxiety property of psychotropic drugs. Many groups (1-7) have reported that anti-anxiety drugs increase the punished responding. In the punishment experiment, differences of the experimental situations, such as schedule programming, reinforcer and drug experience of the experimental animal etc. may affect 
the change of punished responding after the drugs. However, few systematic studies concerning these basic methodological problems have been done. In the present work, we examined the effect of diazepam on the three types of conditioned response-suppression which were produced under the fixed ratio (FR30) schedule of food and/or water reinforcements.

The animals used were 52 adult male rats of the Wistar strain, obtained from the breeding colony of Gunma University, Medical School. At the start of the experiment, the animals were about 15 weeks of age and weighed $300-350 \mathrm{~g}$. They were divided into 2 groups of 25 and 27 , and food or water was not given thereby reducing the body weight to about $85 \%$ of their free-feeding or free-drinking weights. When it was confirmed that the animals strongly demanded the food or water, a training of the rats under the FR30 schedule of food or water reinforcement was started. The reinforcer in each schedule was a food pellet of $45 \mathrm{mg}$ (Japan Clea Co., Tokyo) or $0.05 \mathrm{ml}$ of water.

After establishment of the FR30 behavior, three kinds of conditioned response-suppression were produced by the following three procedures: In the first; when visual and auditory stimuli generated by the sounding of a speaker and lighting of a pilot lamp were presented (alarm period) simultaneously, every 30th response (lever-pressing) was reinforced together with an electric shock of $100 \mathrm{~V}, 0.2 \mathrm{~mA}, 50 \mathrm{~Hz} \mathrm{AC}$ for $0.3 \mathrm{sec}$ as a punishment for the responding. In addition to this situation, an unavoidable shock of the same intensity was delivered to the rat at the termination of the alarm period. In the non-stimulus presentation period (safe period), every 30th response was reinforced without the electric shock. In the second; the experimental condition was the same as the 1st procedure except for the unavoidable shock not being given to the rat. In the third; the rat never actually received the electric shock but no reinforcement was given during the visual and auditory stimuli presentation period ( $\mathrm{S}^{\boldsymbol{A}}$ period). Every 30th response was reinforced in the non-stimulus presentation period ( $\mathrm{S}^{\mathrm{D}}$ period). In a $1 \mathrm{hr}$ experimental session, the safe or $\mathrm{S}^{\mathrm{D}}$ period, and the alarm or $\mathrm{S}^{\Delta}$ period were alternated every $5 \mathrm{~min}$.

Diazepam (Cercine Inj., Takeda) $0.5 \mathrm{mg} / \mathrm{kg}$ was given s.c. to the rats in the present experiment as a sample of anti-anxiety drugs. It has been considered that $0.5 \mathrm{mg} / \mathrm{kg}$ s.c. of the drug is an optimum dose in the FR30 punishment experiment (6) in which the inhibitory effect of the drug on the responding in the safe period is scarcely observed after the single administration. The original preparation of diazepam was diluted 10 times by $10 \%$ propylene glycol vehicle, and was given immediately before the start of the experiment. In addition, the drug was given once a day for 10 days. The behavior of rats was observed for $1 \mathrm{hr}$ after the drug administration.

Figure 1 shows changes of the responses in the alarm and $\mathrm{S}^{\lrcorner}$periods as well as those in the safe and $\mathrm{S}^{\mathrm{D}}$ periods after the repeated administration of diazepam $0.5 \mathrm{mg} / \mathrm{kg}$ s.c. In this figure, results in the 1st, 5th and 10th administrations are shown. The control data are those in the propylene glycol vehicle administration alone.

In the control experiment, the response rate in the safe period was $50-65 / \mathrm{min}$, and the response rate in the alarm period was $1-2.5 /$ min during the two punishment schedules. 


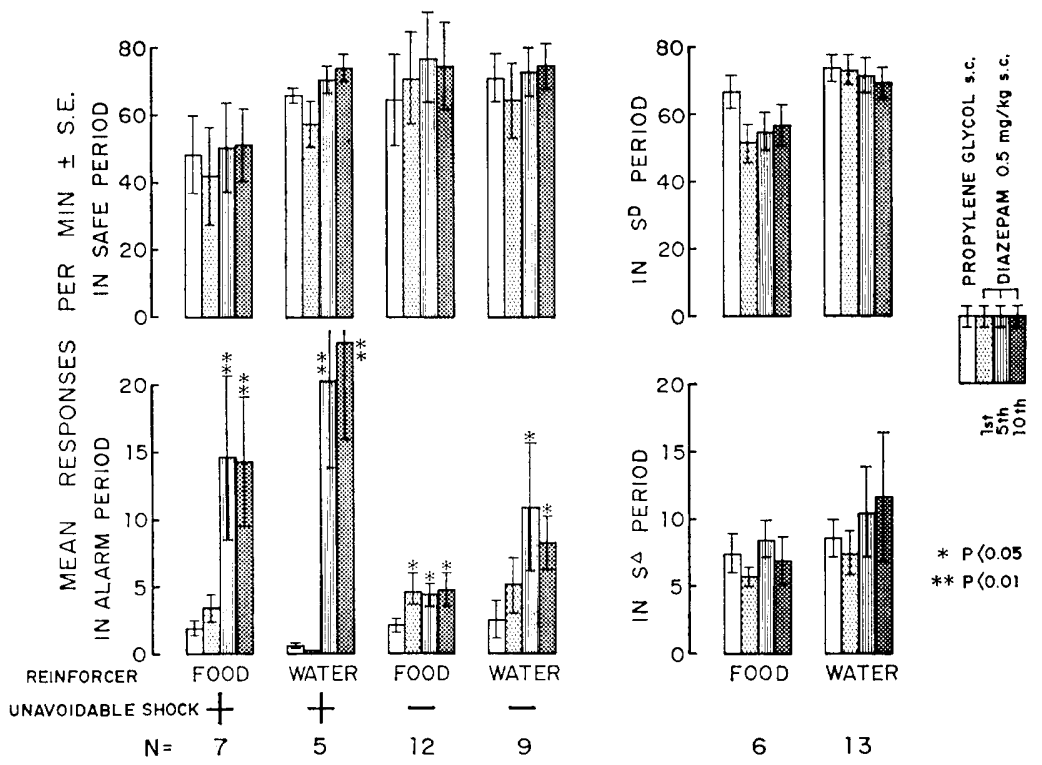

FIG. 1. Effects of daily administration of diazepam $0.5 \mathrm{mg} / \mathrm{kg}$ s.c. on the respondings of rats under the FR30 punishment schedules of food or water reinforcement with or without the unavoidable shock, and FR30 $\mathrm{S}^{\mathrm{D}}-\mathrm{S}^{4}$ schedule of food or water reinforcement.

Upper panels: Response rates in the safe period (left 4 panels) and $\mathrm{S}^{\mathrm{D}}$ period (right 2 panels), in which every 30 th response was reinforced.

Lower panels: Response rates in the alarm period (left 4 panels) and $\mathrm{S}^{\boldsymbol{A}}$ period (right 2 panels), in which every 30th response was reinforced with the electric shock (former case) and no reinforcement was given (latter case)

Data of the 1st, 5th and 10th administration days as well as those of the propylene glycol vehicle administered on preceding days are shown in this figure.

* indicates the significant different from the propylene glycol vehicle administered control level ( $\mathrm{p}<0.05$, Student's $t$-test). $\quad{ }^{* *} \mathrm{p}<0.01$.

Diazepam increased the punished responses, though the change was not so marked within the 2nd-3rd administration. The maximum effect of diazepam was observed 20-30 min after the administration, and was markedly enhanced until the 5th administration according to the repetition. Thereafter almost the same behavioral change was reproduced. The increase of punished responses after diazepam was observed more markedly in the rats under the schedule associated with the unavoidable shock than in those without the shock. No change was observed in the effect of diazepam from the differences of the reinforcer.

On the other hand, the rats also displayed a lower response rate in the $S^{\Delta}$ period than in the $S^{D}$ period. Here the response rate in the $S^{D}$ period was about $70 / \mathrm{min}$, and the response rate in the $S^{\Delta}$ period was $7-8 / \mathrm{min}$. No marked change was observed in the respondings in either the $\mathrm{S}^{\mathrm{D}}$ or $\mathrm{S}^{\mathcal{A}}$ period after the repeated administration of diazepam, regardless of the reinforcers.

The present experiment demonstrates that the response rate in the alarm period, which is extremely low as compared with that in the safe period, progressively increases without any marked change of the response rate in the safe period following several administrations 
of diazepam. The change may not be due to the accumulation of the drug after the repeated administrations. This is because, a similar progressive increase of the punished responses was observed even after the weekly administration of diazepam (8). Moreover, we (8) and Margules and Stein (9) reported that once produced, the enhancing effect of diazepam or oxazepam on the punished responding by repeated administration was maintained for more than one month even after the discontinuation of the drugs. Diazepam elicited no marked change of the response rate in the $\mathrm{S}^{\lrcorner}$period but increased the response rate in the alarm period. These results suggest that diazepam increases specifically only the punished responses, while not affecting the discriminative ability of the rats.

There was no marked difference in the effect of diazepam between food and water reinforcements. However increase of the punished responses after diazepam was observed more markedly in the rats under the schedule with the unavoidable shock than in those under the schedule without the shock. Under the conditioned suppression schedule of Estes and Skinner (10), in which only the unavoidable shock was given to the rat at the termination of conditioned stimulus, the rat displayed a low response rate during the stimulus presentation period (conditioned emotional response; CER). Many workers (11-13) have reported that CER is attenuated after anti-anxiety drugs. But the CER is extremely unstable and examination of the drug effect is difficult. The role of the unavoidable shock in the punishment schedule cannot be explained by the present experiment. However, in order to evaluate the susceptibility of animals to the anti-anxiety drugs, the unavoidable shock and the repeated administration may play important roles in the punishment experiment.

\section{REFERENCES}

1) Geller, I. And Seifter, J.: The effects of meprobamate, barbiturates, d-amphetamine and promazine on experimentally induced conflict in the rat. Psychopharmacol. 1, 482-492 (1960)

2) Geller, I. And Seifter, J.: The effects of monourethan, di-urethans and barbiturates on a punishment discrimination. J. Pharmacol. exp. Ther. 136, 284-288 (1962)

3) Kelleher, R.T. and Morse, W.H.: Escape behavior and punished behavior. Fedn. Proc. 23, 808-818 (1964)

4) McMillan, D.E.: Drugs and punished responding I: Rate-dependent effects under multiple schedules. J. exp. Anal. Behav. 19, 133-145 (1973)

5) McMillan, D.E.: Determinants of drug effects on punished responding. Fedn. Proc. 34, 1970-1979 (1975)

6) TADOKORO, S. AND TADOKORO, N.: Disparities of diazepam effect depending on its preparation and administration routes investigated behavioral pharmacologically in rats. Japan. J. clin. Pharmacol. 2, 5-13 (1971) (in Japanese)

7) WüttKe, W. and Kelleher, R.T.: Effects of some benzodiazepines on punished and unpunished behavior in the pigeon. J. Pharmacol. exp. Ther. 172, 397-405 (1970)

8) Kuribara, H., Okuizumi, K., Ogawa, H. and Tadokoro, S.: Enhancing effects induced by repeated administration of diazepam on conditioned suppressions in rats. Japan. J. Pharmacol. 26, Supp. 40p (1976)

9) Margules, D.L. ANd Stein, L.: Increase of "antianxiety" activity and tolerance of behavior depression during chronic administration of oxazepam. Psychopharmacol. 13, 74-80 (1968)

10) Estes, W.K. And Skinner, B.F.: Some quantitative properties of anxiety. J. exp. Psychol. 29, 390-400 (1942)

11) Lauener, H.: Conditioned suppression in rats and the effect of pharmacological agents 
thereon. Psychopharmacol. 4, 311-325 (1963)

12) MiczeK, K.A.: Effects of scopolamine, amphetamine and benzodiazepines on conditioned suppression. Pharmacol. Biochem. Behav. 1, 401-411 (1973)

13) Scobie, S.R. and Carske, G.: Chlordiazepoxide and conditioned suppression. Psychopharmacol. 16, 272-280 (1970)

\title{
CHARACTERISTIC HYPERPYREXIA INDUCED BY LiCl AND TRANYLCYPROMINE IN RATS
}

\author{
Kyoichi SHIMOMURA, Yoshihiko SATOH and Jo MORI \\ Research Laboratories, Fujisawa Pharmaceutical Co. Ltd., \\ Yodogawa-ku, Osaka 532, Japan
}

Accepted December 1, 1979

In previous studies $(1,2)$, we showed that tranylcyrpromine (TCP), a monoamine oxidase inhibitor (MAOI), caused a fatal hyperpyrexia in rats which had been given repeated doses of $\mathrm{LiCl}$. This phenomenon is one of the most conspicuous responses concerned with lithium. The present work was an attempt to test whether or not the hyperpyrexia is induced specifically by the combination of $\mathrm{LiCl}$ and TCP.

Male Sprague-Dawley rats weighing 220-280 g, supplied by CLEA Japan Inc., were used. Five to 17 animals were used per group. In one series of experiments, rats were given a drug or an alkali metal once daily for 4 days. Control animals were given $\mathrm{LiCl}$ at a dose of $250 \mathrm{mg} / \mathrm{kg}$ which was used in our previous experiments $(1,2)$. The alkali metals other than $\mathrm{LiCl}$ were given in two doses which were equivalent to that of $\mathrm{LiCl}$ either on the weight or molar basis. On day 4 , these rats were given TCP $4 \mathrm{hr}$ after the last injection of an alkali metal or a drug. In another series of experiments, rats were given $\mathrm{LiCl}$ at a dose of $250 \mathrm{mg} / \mathrm{kg}$ once daily for 4 days. On day 4 , a MAOI was given to rats $4 \mathrm{hr}$ after the last injection of $\mathrm{LiCl}$. In both series of experiments, the rectal temperatures were measured with a thermister probe (Thermo Japan) inserted about $4.5 \mathrm{~cm}$ into the rectum 1, 2, 3 and $4 \mathrm{hr}$ after the injection of a MAOI. Rats were housed in individual cages during the measurement of rectal temperature. All experiments were performed at an ambient temperature of $22.0-24.0^{\circ} \mathrm{C}$. Drugs used were haloperidol (Janssen), fluphenazine dihydrochloride, chlordiazepoxide hydrochloride, chlorpromazine hydrochloride (synthesized in our Research Laboratories), sulpiride and imipramine hydrochloride (Fujisawa), diazepam (CercineTakeda), cyproheptadine hydrochloride (Nihon Merck Banyu), phentolamine mesylate (Regitine, CIBA-Geigy), tranylcypromine, DL-propranolol hydrochloride and nialamide (Sigma), tolazoline hydrochloride and iproniazid phosphate (Aldrich), methamphetamine hydrochloride (Hiropon, Dainippon), $\mathrm{LiCl}, \mathrm{NaCl}, \mathrm{KCl}, \mathrm{RbCl}, \mathrm{CsCl}$ and pargyline hydrochloride (Nakarai Chemicals). TCP and nialamide were suspended in $0.5 \%$ methylcellulose aqueous solution $(0.5 \% \mathrm{MC})$. Haloperidol and sulpiride were dissolved in mini- 